potential of this technique to produce neurological damage.' Any benefits that a cardiopulmonary bypass may allow in terms of surgery will be greatly diminished if intellectual and psychological impairment is a consequence.

On the basis of an interesting study by Nevin et al ${ }^{2}$ Dr Allen emphasises the importance of avoiding hypocapnia before cardiopulmonary bypass The study by Nevin et al, which may point the way, cannot, however, be taken as conclusive evidence of an association between cause and effect. Also, if hyperventilation is the simple cause of neurological deficit then many patients undergoing general anaesthesia with intermitten positive pressure ventilation for all forms of surgery are at risk as there is a tendency withou appropriate monitoring to use a minute volume that errs on the side of hyperventilation rather than hypoventilation with resultant hypocapnia. To my knowledge this hyperventilation does not produce the neuropsychological deficits that are associated with cardiopulmonary bypass operations.

Of far greater importance is the more conten tious issue of acid-base management during hypothermic cardiopulmonary bypass, ${ }^{3}$ which was not discussed by Dr Allen. Arterial carbon dioxide tension can be manipulated to produce either $\mathrm{pH}$ or alpha stat ${ }^{2}$ acid-base management. It is now clear that $\mathrm{pH}$ stat acid-base management produces cerebral hyperaemia with an uncoupling of oxygen supply from demand because of pressure passive cerebral blood flow. ${ }^{+}$In contrast, alpha stat management maintains cerebral autoregulation and cerebral blood flow remains independent of pressure. Until the neuropsychological effects of these two forms of acid-base management are investigated it would seem logical to use alpha stat control.

Also, in Dr Allen's list of pharmacological candidates for cerebral protection isoflurane was omitted. As isoflurane has cerebral protective effects, albeit in animals under differing circumstances, ${ }^{5}$ it should also be listed as a candidate.

R PETER ALSTON

Department of Anaesthesia

University of Glasgow,

Glasgow G31 2ER

1 Allen CMC. Cabbages and CABG. Br Med $\mathcal{F}$ 1988;297:1485-6. 10 December.)

2 Nevin M, Colchester AC, Adams S, Pepper GR. Evidence for involvement of hypocapnia and hypoperfusion in aetiology of neurological deficit after cardiopulmonary bypass. Lance 1987;ii: 1493.5

3 White FN. Hypothermia. Lessons from comparative physiology. In: Utley JR, ed. Pathophysiology and techniques of cardiopulmonary bypass. Vol I. Baltimore: Williams and Wilkins, pulmonary bypass $145-50$.

4 Murkin JM. Cerebral hyperperfusion during cardiopulmonary bypass: the influence of $\mathrm{PaCO}_{2}$. In: Hillerman $\mathrm{M}$, ed. Brain injury and protection during heart surgery. Boston: Martinus Nyhoff, 1988:47-66.

5 Newberg LA, Michenfelder JD. Cerebral protection by isoflurane during hypoxaemia or ischaemia. Anesthesiology 1983 59:29-35

\section{Sensitivity and specificity of Rinne tuning fork test}

SIR, - Drs G G Browning and I R C Swan conclude that a Rinne positive response - that is, a negative test result - in a patient presenting with impaired hearing and an otoscopically normal tympanic membrane should be interpreted with caution because of the test's fairly low sensitivity in detecting a clinically relevant air-bone conduction gap.

If this meant that audiometry is indicated in al such patients the Rinne test would be useless as all patients would have to be referred for audiometry, regardless of the Rinne test result. The decision to do audiometry should, however, be based not on sensitivity and specificity but on the probability of a clinically relevant air-bone gap, given the test result. This posterior probability is, apart from sensitivity and specificity, a function of the previous probability of a clinically relevant airbone gap, which is determined by the diagnostic setting - that is, high in patients complaining of loss of hearing and low in the case of screening by the Rinne test. In addition, if in some way a Rinne negative response contributed to the decision about referring the study subjects to the otological clinic the sensitivity of the test in genera practice could be seriously overestimated and the specificity underestimated. Unfortunately, such information on patient selection is missing.

In principle, it would be possible to calculate the posterior probability of a clinically relevant air-bone gap from the sensitivity and specificity and the pertaining prior probability. To do so with the sensitivity and specificity from the study could, however, be highly misleading. The author present the sensitivity and specificity as a function of air-bone gap cut off points, separating patients with and without clinically relevant air-bone gaps. Unfortunately, this does not prevent sensitivity and specificity from still being dependent on the actual distribution of air-bone gaps in this particular study population.

This problem could have easily been circum vented by presenting the data as the probability of a Rinne negative response for different levels of air-bone gap. From this readers can calculate directly posterior probability distribution of air-bone gaps for their own patients if the prior distribution in their diagnostic setting is known. Only from this can the likelihood of missing a clinically relevant air-bone gap in patients with a Rinne positive response be estimated and the usefulness of the Rinne test in a particular diagnostic setting be appreciated.

CAREL THIJS

PIETER LEFFERS

Department of Epidemiology,

Riiksuniversiteit Limburg,

6200 MD Maastricht,

The Netherlands

1 Browning GG, Swan IRC. Sensitivity and specificity of Rinne tuning fork test. Br Med f 1988;297:1387-2. 26 November.

AUTHORS' REPLY,-Drs Thijs and Leffers raise an interesting methodological point but also appear to be under a misconception as to the role of the Rinne test.

The sensitivity and specificity of the Rinne tuning fork test could perhaps be differently reported, not as a dichotomy as to whether a patient passes or fails a certain criterion of air-bone gap but for different ranges of air-bone gaps - for example, 20-25 dB. To achieve a comparable degree of precision would have required a much larger study, probably four times as large as our own - that is, about 500 individuals. This was considered and rejected because the results were unlikely to be materially different from those of our smaller study. This was of 127 adults with otological symptoms attending an otolaryngological clinic in the United Kingdom and reported the sensitivity and specificity of the Rinne test in detecting air-bone gaps of different magnitudes. Thus the results are likely to apply to all similar practices and address the chances of detecting significant air-bone gaps. It is correct to state that fuller data would be more accurate if the population under study were to be materially different in its distribution of air-bone gaps. Such data would, however, be of use only to individuals who had taken the trouble to record the distribution of air-bone gaps in their population. Such individuals must be rare and are unlikely to rely too heavily, if at all, on the Rinne tuning fork test.

What to us is incorrect is Dr Thijs's and Dr Leffers's inference that the Rinne test might be used as a screening method to decide which patients should be referred for audiometry. In our opinion audiometric assessment will be necessary in anybody who considers his or her hearing to be impaired. If informal testing is considered necessary the best test to detect an impairment is free field voice testing, which requires no instrumentation, is relatively easy to perform, and in trained hands is highly sensitive, impaired individuals being unable to repeat what is said in a whispered voice at $0.6 \mathrm{~m}$.

In the light of findings from our own adult study and from similar paediatric studies ${ }^{2}$ we therefore consider that the Rinne tuning fork test, if it is to be used at all, should be used only as a back up to puretone audiometry. It has no place in nonspecialist settings.

GEORGE G BROWNING IAIN R C SWAN

Department of Otolaryngology

Roval Infirmary

Glasgow G+ OSF

1 Swan IRC The whispered voice as a screening test for hearing impairment. F R Coll Gen Pract 1985;35:197.

2 Capper JW'R, Slack RWT. Maw AR. Tuning fork tests in children an evaluation of their usefulness :. I Laryngol Otol $1987 ; 101: 780-3$

\section{Trouble ahead for clinical trials}

SIR, - It is distressing that Professor Robert Levine should link the important contrast between "pragmatic" and "fastidious" clinical trials with a quite imaginary opposition between doctors and statisticians.' A group of French medical statisticians, one of them a doctor, first called attention to the contrast and its far reaching implications for the design and conduct of clinical trials, ${ }^{23}$ and it is now widely recognised.

As a separate issue statisticians are sometimes "fastidious" in their insistence on such aspects of good experimentation as adequate sample sizes and randomisation; my experience is that such insistence is often welcomed by medical colleagues, if not when planning the trial then later when the results come to be submitted for publication.

Department of Epidemiology and
Population Sciences,
London School of Hygiene and Tropical Medicine,

London School of Hy

London WC1E 7HT

1 Smith R. Trouble ahead for clinical trials. Br Med f 1988;297: 1567. (17 December.)

2 Schwartz D, Lellouch J. Explanatory and pragmatic attitudes in therapeutic trials. $\mathcal{F}$ Chronic Dis 1967;20:637-48.

3 Schwartz D, Flamant R, Lellouch J. L'essai therapeutique ches l'homme. Paris: Flammarion, 1970. (Trans Clinical trials. London: Academic Press, 1980.

\section{The cases for and against prescribing generic drugs}

SIR,-Dr Joe Collier finds it difficult to see why generic prescribing has not been universally adopted.' In hospital practice there is no problem but in general practice there remains a lack of confidence in generic preparations.

Inspection of the generic preparations stocked by some retail pharmacists shows why; their stock commonly consists of the cheapest brands, often manufactured abroad. This is in direct contrast to the hospital service, whose generic drugs are carefully vetted by the regional pharmacist, manufacturing premises inspected, and batch testing performed. If any untoward reaction occurs in patients it may readily be related to the generic product used. In general practice the prescribing doctor has no information on either the manufacturer or on any change of brand.

Would Dr Collier be prepared to buy corned beef from a corner grocer in a tin marked only "corned beef," with no information on the manu- 